\title{
Data Mining to Facilitate the Trading
}

\author{
Rajesh Kumar \\ 943A/28, Bharat colony, Rohtak, Haryana
}

\begin{abstract}
Financial sector is always full of insecurity, owing to volatility in the financial sector, most of the investors fails to book the profit. It has been observed in this study that maximum percentage of return of a security or indices follows the Benford's law when price of the security or indices breaks the volume weighted moving average in upper trend. Results of this study can be used by investors in taking intelligent decisions. This model can be used in machine learning, which can facilitate the investors in the decision support system.
\end{abstract}

\section{Keywords}

Moving Averages, Data mining, Classification, Genetic algorithm, Benford's law

\section{INTRODUCTION}

Globalization and information technology revolution has created a huge amount of data. To tap the potential of this data, data mining techniques are required. As data sets have grown in size and complexity, the need of special tools like neural networks, genetic algorithms, decision trees and support vector machines emerged. These tools has helped the data analyzers in taking a wise and informed decisions. Data mining is the process of analyzing the data in a different perspective and summarizing it so that it can be a useful information, with the intention of uncovering hidden patterns from a large data sets[6]. It uses the statistical methods and artificial intelligence algorithms in indexing and storing of data bases so that information retrieved from it can be rationalized with an efficiency. Knowledge discovery in databases field is concerned with the development of methods and techniques for making sense of data[7]. Data mining has been applied to a number of financial applications including development of trading models, investment decision, loan assessment, portfolio optimization, fraud detection, bankruptcy prediction, real-estate assessment, and so on. The competitive advantages achieved by data mining include increased revenue[9]. The goals of data mining are briefly described in section 1.1,1.2,1.3 [8].

\subsection{Classification}

In the data analysis, it is essential to put the instances under the test in a desired class. It categorizes the instance in a particular category. The ability of a classifier refers to the ability to correctly classifying the unseen data in a class by taking a clue from the training data set Following methods are being used in classification.

\subsubsection{Rule based methods}

Data mining system learns from examples. It formulates classification rules in order for the prediction of future. For instance, in customer database in a bank, a query is made whether a new customer applying for a loan is a good investment or not? Typical rule are as follows which may be produced by rule based systems

if STATUS $=$ married and INCOME $>10000$ and HOUSE_OWNER and has a VEHICLE =yes then INVESTMENT_TYPE $=$ good

\subsubsection{Neural Network}

Neural network can be used in the classification purpose. They simulate the human brain . Artificial Neuron can be supervised or unsupervised. They are composed of many units called neuron. Artificial neuron require long training time and are black box which lacks explanation, but it has high tolerance to noisy data so it can classify untrained data . Being the tolerant to noisy data, neural network are widely used in industrial applications.

\subsubsection{Bayesian classification}

Bayesian classification predicts class membership using Bayes theorem, which further uses probability. Its performance is comparable to selected neural network and decision tree. They can facilitate decision making even on computational intractable problems.

\subsubsection{Support Vector Machine}

Support vector machine can classify both linear and non linear data..Data from two classes are separated by hyper plane, Support vector machine finds the hyper plane by using training data. Its training is slow but accuracy is very high and SVM can model non linear problems also.

\subsubsection{Genetic Algorithm}

Genetic algorithm has taken a queue from the natural evolution. Initial population is created using randomly generated rules. Each rule is represented by a string of bits. In next generation, survival of the fittest selects the fittest rules. Crossover and mutation are used in production of offspring. In cross over substring of a rule are exchanged with substring of another rule. In mutation randomly selected bits are inverted. It being an iterative purpose, a rule will get position in next generation, if it crosses a threshold. Genetic algorithm can be used in classification besides optimization purpose.

\subsubsection{Case Based Reasoning}

Case based reasoning stores the old instances in a database to classify the unseen instances as equal to stored instance, if it does not exist than it search for another very similar instance.

\subsection{Association}

Rules that associate one attribute of a relation to another attribute approaches are the most efficient means of discovering such rules like in supermarket database. If a certain percentage of all the records that contain items $\mathrm{A}$ and $\mathrm{B}$ also contain item $\mathrm{C}$ the specific percentage of occurrences is the confidence factor of the rule .Association rule mining is useful in mining single dimensional Boolean association rule from the transactional databases, it can be further extended for mining multilevel rule from the transactional databases.

\subsection{Sequence/Temporal}

Sequential pattern functions identifies the collections of related records and detects frequently occurring pattern over a period of time under study .Difference between sequence rules and other rules is the temporal factor. For example - Retailers database can be used to discover the set of purchases that frequently precedes the purchase of a microwave oven or harvesting season. 
Rest of the paper is organized as follows

- $\quad$ Section 2 covers Moving Averages

- $\quad$ Section 3 covers Benford's law.

- Section 4 covers Data Analysis .

- Section 5 covers Conclusion.

- Section 6 covers References.

\section{MOVING AVERAGES}

In statistics, a moving average ,rolling average or running average is a calculation to analyze data points by creating a series of averages of different subsets of the full data set. A moving average may also use unequal weights for each data value in the subset to emphasize particular values in the subset[10]. Exponentially-weighted moving average tracks of all prior sample means. WMA weights samples in geometrically decreasing order so that the most recent samples are weighted most highly while the most distant samples contribute very little. In exponential weighted moving average smoothing scheme begins by setting $\mathrm{S} 2$ to $\mathrm{y} 1$, where $\mathrm{Si}$ stands for smoothed observation or EWMA, and y stands for the original observation. The subscripts refer to the time periods, $1,2, \ldots, \mathrm{n}$. For the third period.

$\mathrm{s} 3=\propto \mathrm{y}_{2}+(1-\propto) \mathrm{s}_{2}$

and so on. There is no S1; the smoothed series starts with the smoothed version of the second observation.

$\mathrm{s}_{\mathrm{t}}=\propto \mathrm{y}_{\mathrm{t}-1}+(1-\propto) \mathrm{s}_{\mathrm{t}-1} \quad 0 \propto \leq 1 \mathrm{t} \geq 3$

This is the basic equation of exponential smoothing and the constant or parameter $\propto$ is called the smoothing[12]. The speed at which the older responses are dampened (smoothed) is a function of the value of $\propto$. When $\propto$ is close to 1 , dampening is quick and when $\propto$ is close to 0 , dampening is slow [12].

\section{BENFORD LAW}

Initially it seems that digits are equally likely to distribute in a number that forms an observations, but this conception was wrong and demystified by Benford law [15]. Benford law states that the probability of any digit D from 1 to 9 being the first digit is where distribution is not uniform is given by

$\log _{10}\left(1+\frac{1}{D}\right)$

Whereas probability at $2^{\text {nd }}$ digit can be given by

$\sum_{D 1=1}^{9} \log _{10}\left(1+\frac{1}{\mathrm{D} 1 \mathrm{D} 2}\right)$

Where $\mathrm{D}_{2}=\{0,1----9\}$

And probability of combination of $1^{\text {st }}$ digit and $2^{\text {nd }}$ digit can be given by the formula.

$P(D 1 D 2)=\log _{10}\left(1+\frac{1}{D 1 D 2}\right)$

Whereas D1D2 $=\{10,11------, 99\}$
Table 1. Frequencies based on Benford's Law[13]

\begin{tabular}{|c|c|c|c|c|}
\hline Digit & 1st Place & $2^{\text {nd }}$ place & $3^{\text {rd }}$ Place & $4^{\text {th }}$ Place \\
\hline 0 & & 0.11968 & 0.10178 & 0.10018 \\
\hline 1 & 0.30103 & 0.11389 & 0.10138 & 0.10014 \\
\hline 2 & 0.17609 & 0.19882 & 0.10097 & 0.1001 \\
\hline 3 & 0.12494 & 0.10433 & 0.10057 & 0.10006 \\
\hline 4 & 0.09691 & 0.10031 & 0.10018 & 0.10002 \\
\hline 5 & 0.07918 & 0.09668 & 0.09979 & 0.09998 \\
\hline 6 & 0.06695 & 0.09337 & 0.0994 & 0.09994 \\
\hline 7 & 0.05799 & 0.0935 & 0.09902 & 0.0999 \\
\hline 8 & 0.05115 & 0.08757 & 0.09864 & 0.09986 \\
\hline 9 & 0.04576 & 0.085 & 0.09827 & 0.09982 \\
\hline
\end{tabular}

\section{DATA ANALYSIS}

Sixty five instances under the study were compared with ten days volume weighted moving average. Whenever price of an instance breaks the resistance of moving average, It has given the positive return and further it followed the Benford's law.

Table 2. Data of VWMA10 and security top price achieved.

\begin{tabular}{|l|r|r|r|}
\hline Script & \multicolumn{1}{|l|}{ VWMA } & Top & \multicolumn{1}{l|}{$\begin{array}{l}\text { Percentage } \\
\text { Change }\end{array}$} \\
& ten days & & 7.6 \\
\hline NIFTY & 5750 & 6187 & 1.82401621 \\
\hline NIFTY & 5921 & 6029 & 11.1757448 \\
\hline NIFTY & 5673 & 6307 & 2.79237845 \\
\hline NIFTY & 6088 & 6258 & 2.20062351 \\
\hline NIFTY & 5453 & 5573 & 0.7638191 \\
\hline NIFTY & 5627 & 5660 & 0.58645815 \\
\hline NIFTY & 4975 & 5013 & 0.89344909 \\
\hline NIFTY & 5068 & 5316 & 4.839348 \\
\hline NIFTY & 2807 & 3812 & 35.803348 \\
\hline NIFTY & 4373 & 4714 & 7.79785045 \\
\hline NIFTY & 4921 & 5052 & 2.66206056 \\
\hline NIFTY & 4998 & 5045 & 0.94037615 \\
\hline NIFTY & 4995 & 5361 & 7.32732733 \\
\hline NIFTY & 5145 & 5368 & 4.33430515 \\
\hline Reliance & 800 & 835 & 4.375 \\
\hline Reliance & 799 & 839 & 5.00625782 \\
\hline & & & \\
\hline & & & \\
\hline
\end{tabular}




\begin{tabular}{|l|r|r|r|}
\hline Reliance & 867 & 881 & 1.61476355 \\
\hline Reliance & 853 & 908 & 6.44783118 \\
\hline Reliance & 878 & 895 & 1.93621868 \\
\hline Reliance & 792 & 900 & 13.6363636 \\
\hline Reliance & 731 & 863 & 18.0574555 \\
\hline Reliance & 716 & 729 & 1.81564246 \\
\hline Reliance & 729 & 816 & 11.9341564 \\
\hline eliance & 808 & 912 & 12.8712871 \\
\hline Reliance & 801 & 835 & 4.24469413 \\
\hline ONGC & 315 & 340 & 7.93650794 \\
\hline ONGC & 325 & 331 & 1.84615385 \\
\hline ONGC & 282 & 289 & 2.4822695 \\
\hline ONGC & 273 & 287 & 5.12820513 \\
\hline ONGC & 278 & 299 & 7.55395683 \\
\hline ONGC & 284 & 292 & 2.81690141 \\
\hline Kajaria & 70 & 112 & \\
\hline Kajaria & 107 & 119 & 11.2149533 \\
\hline Kajaria & 100 & 185 & \\
\hline Kajaria & 168 & 178 & 5.95238095 \\
\hline Kajaria & 176 & 257 & 46.0227273 \\
\hline Kajaria & 188 & 249 & 32.4468085 \\
\hline Kajaria & 235 & 251 & 6.80851064 \\
\hline Kajaria & 247 & 308 & 24.6963563 \\
\hline Gold ETF & 1274 & 1334 & 4.70957614 \\
\hline Gold ETF & 1258 & 1458 & 15.8982512 \\
\hline Gold ETF & 1417 & 1471 & 3.81086803 \\
\hline Gold ETF & 1068 & 1343 & 25.7490637 \\
\hline Gold ETF & 1304 & 1391 & 6.67177914 \\
\hline Gold ETF & 1338 & 1360 & 1.64424514 \\
\hline Gold ETF & 1335 & 1399 & 4.79400749 \\
\hline Gold ETF & 1400 & 1542 & 10.1428571 \\
\hline Gold ETF & 1493 & 1519 & 1.74146015 \\
\hline Axis bank & 1356 & 1536 & 13.2743363 \\
\hline
\end{tabular}

\begin{tabular}{|l|r|r|r|}
\hline Axis bank & 1009 & 1218 & 20.7135778 \\
\hline Axis bank & 1117 & 1279 & 14.5031334 \\
\hline Axis bank & 928 & 1278 & 37.7155172 \\
\hline Axis bank & 1015 & 1034 & 1.87192118 \\
\hline Axis bank & 997 & 1110 & 11.334002 \\
\hline Axis bank & 1026 & 1352 & 31.7738791 \\
\hline Axis bank & 1256 & 1449 & 15.366242 \\
\hline Axis bank & 1272 & 1337 & 5.11006289 \\
\hline Axis bank & 1081 & 1103 & 2.03515264 \\
\hline Axis bank & 367 & 778 & 111.989101 \\
\hline Axis bank & 937 & 996 & 6.29669157 \\
\hline Asian Paints & 2039 & 2847 & 39.6272683 \\
\hline Asian Paints & 2652 & 2887 & 8.8612368 \\
\hline Asian Paints & 2515 & 3167 & 25.9244533 \\
\hline Asian Paints & 3015 & 3313 & 9.88391376 \\
\hline Asian Paints & 3139 & 3263 & 3.95030264 \\
\hline Asian Paints & 3700 & 3946 & 6.64864865 \\
\hline
\end{tabular}

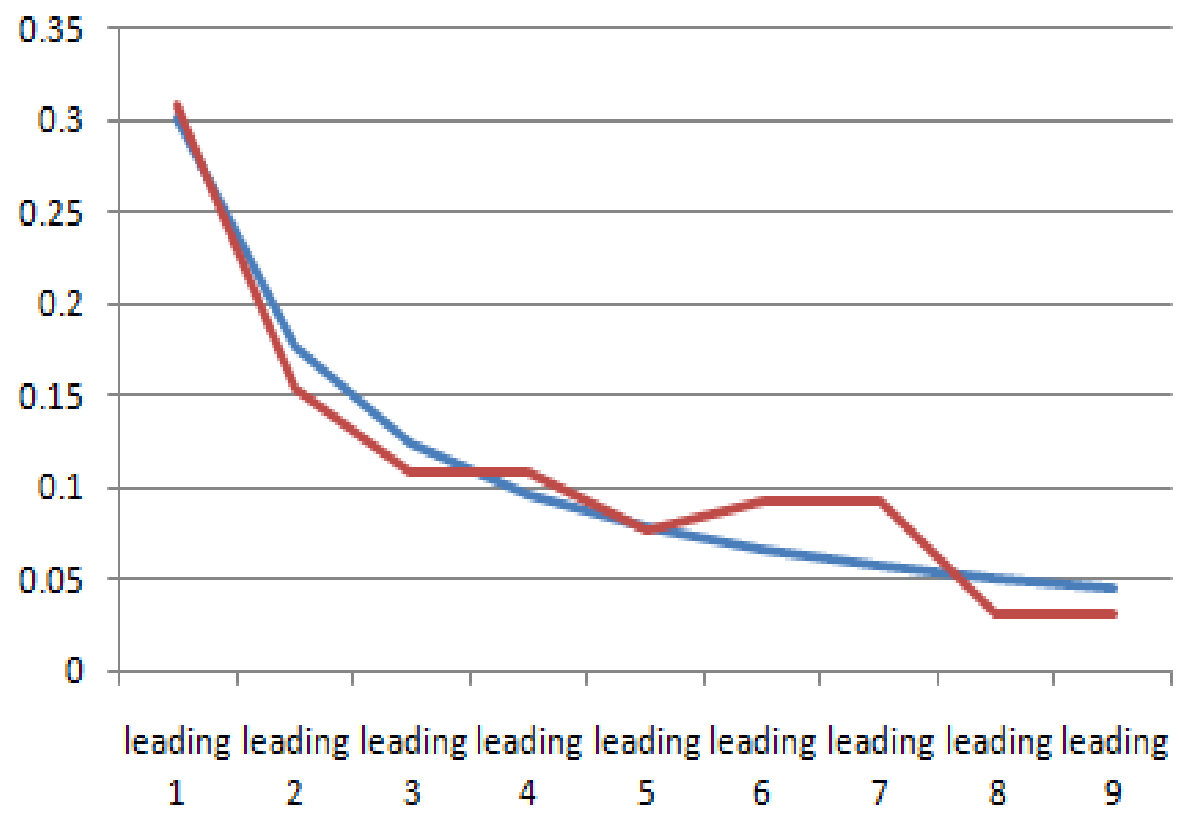

$Y$ axis occureces samples

Fig. 1: Comparison of Benford's law with the returns leading digits occurrences/samples 


\section{CONCLUSION}

Financial sector is always over shadowed by volatility. Investors has to take the returns by beating the volatility. To tap the potential of huge amount of data from the financial sector, this study can be very useful. Investor can use the heuristics provided by this study in taking the informed decisions that maximum probability of percentage returns provided by a security when it breaks the resistance of VWMA of ten days is a digit starting with one.

\section{REFERENCES}

[1] Rokach, Lior; Maimon, O. (2008 "Data mining with decision trees: theory and applications.", World Scientific Pub Co Inc. ISBN 978-9812771711.

[2]Varun Chandola et al,(2009)," Anamoly detection survey.", ACM Computing Surveys, Vol. 41(3), Article 15.

[3] Shyam Boriah, Varun Chandola and Vipin Kumar,(2008),"Similarity measure of categorical datas.", In Proceedings of SIAM Data Mining Conference, Atlanta, GA.

[4] Principles of Data Mining.( 2007). doi:10.1007/978-1-84628766-4. ISBN 978-1-84628-765-7.

[5]Varun Chandola, Shyam Boriah, and Vipin Kumar,(2009) In Proceedings of SIAM Data Mining Conference, Sparks.

[6]Kantardzic, Mehmed (2003)," Data Mining: Concepts, Models, Methods, and Algorithms.", John Wiley \& Sons. ISBN 0-471-22852-4. OCLC 50055336.

[7]Usama Fayyad, Gregory Piatetsky-Shapiro, and Padhraic Smyth,(1996) ,’To Knowledge Discovery in Databases.”,6, American Association for Artificial Intelligence. AI Magazine Volume 17 Number 3.

[8] Jiawei Han and Michelin Kamber ,(2006) "Data Mining Concepts and Techniques.”, $2^{\text {nd }}$ edition, Morgan Kaufman.

[9] Dongsong Zhang and Lina Zhou,(2004) "Discovering Golden Nuggets: Data Mining,in Financial Application. “,IEEE Transactions on systems,man and cybernetics -Part C: Applications and review,Vol. 34, No. 4,

[10] pages downloaded from Engineering statistics handbook http://www.itl.nist.gov/div898/handbook/pmc/section4/pmc 431.htm
[11]Kalgonda , Koshti. , Ashokan.(2011)," Exponentially weighted moving average control chart.”, Asian journal of management research, Vol2.

[12] Everette,Ronald ,(1995)", Production and operation management concepts models and",5th edition, Prentice Hall of India.

[13]Durtschi, Cindy and William Hillison and Carl Pachini. (2004) "The Effective Use of Benford's Law to Assist in Detecting Fraud in Accounting Data", Journal of Forensic Accounting 1524-5586/Vol. V: 17-34.

[14]Nigrini, M. J. (1997),’Digital Analysis Tests and Statistics. ",Allen, Texas: The Nigrini Institute, Inc. Mark_Nigrini@classic.msn.com,1997

[15]Mark, j . Nigrini and Linda ,(1997),'The use of benford law as an aid in analytical procedure ",Auditing a journal of practice and theory, vol16,no2.

[16]Agrawal, R., and Psaila, G. 1995. Active Data Mining. In Proceedings of the First International Conference on Knowledge Discovery and Data Mining (KDD-95), 3-8. Menlo Park, Calif.: American Association for Artificial Intelligence.

[17]Agrawal, R.; Mannila, H.; Srikant, R.; Toivonen, H.;and Verkamo, I.(1996) Fast Discovery of Association Rules. In Advances in Knowledge Discovery and Data Mining, eds.

[18]Smyth, and R. Uthurusamy, (1993)" Detection of Abrupt Changes: Theory and Application.”, Englewood Cliffs, N.J.: Prentice Hall, 514-560. Menlo Park, Calif.: AAAI Press Basseville, M., and Nikiforov, I. V.

[19]Brachman, R., and Anand, T., (1996) "The Process of Knowledge Discovery in Databases: A Human-Centered Approach". In Advances in Knowledge Discovery and Data Mining, 37-58, Edition.

[20] Hall, J.; Mani, G.; and Barr, D. 1996 "Applying Computational Intelligence to the Investment Process" ,In Proceedings of CIFER-96: Computational Intelligence in Financial Engineering. Washington ,D.C.: IEEE Computer Society. 